\title{
CNTNAP2 polymorphisms and structural brain connectivity: A diffusion-tensor imaging study
}

\section{Citation}

Clemm von Hohenberg, Christian, Marlene C. Wigand, Marek Kubicki, Gregor Leicht, Ina Giegling, Susanne Karch, Annette M. Hartmann, et al. 2013. "CNTNAP2 Polymorphisms and Structural Brain Connectivity: A Diffusion-Tensor Imaging Study." Journal of Psychiatric Research 47 (10) (October): 1349-1356. doi:10.1016/j.jpsychires.2013.07.002.

\section{Published Version}

doi:10.1016/j.jpsychires.2013.07.002

\section{Permanent link}

http://nrs.harvard.edu/urn-3:HUL.InstRepos:28539568

\section{Terms of Use}

This article was downloaded from Harvard University's DASH repository, and is made available under the terms and conditions applicable to Other Posted Material, as set forth at http:// nrs.harvard.edu/urn-3:HUL.InstRepos:dash.current.terms-of-use\#LAA

\section{Share Your Story}

The Harvard community has made this article openly available.

Please share how this access benefits you. Submit a story.

\section{Accessibility}




\title{
CNTNAP2 polymorphisms and structural brain connectivity: a diffusion-tensor imaging study
}

\author{
Christian Clemm von Hohenberg ${ }^{1,2,3}$, Marlene C. Wigand ${ }^{1,2,3}$, Marek Kubicki ${ }^{1,4}$, Gregor \\ Leicht $^{3}$, Ina Giegling ${ }^{2}$, Susanne Karch ${ }^{2}$, Annette M. Hartmann², Bettina Konte ${ }^{2}$, Marion \\ Friedl $^{2}$, Thomas Ballinger ${ }^{1}$, Ryan Eckbo ${ }^{1}$, Sylvain Bouix ${ }^{1,4}$, Lorenz Jäger ${ }^{5}$, Martha E. \\ Shenton ${ }^{1,4,6}$, Dan Rujescu ${ }^{2,7}$, and Christoph Mulert ${ }^{3}$ \\ ${ }^{1}$ Psychiatry Neuroimaging Laboratory, Brigham and Women's Hospital and Harvard Medical \\ School, Boston, MA \\ ${ }^{2}$ Department of Psychiatry, Faculty of Medicine, Ludwig-Maximilians-Universität, Munich, \\ Germany \\ ${ }^{3}$ Psychiatry Neuroimaging Branch, Imaging Center Neurolmage Nord and Department of \\ Psychiatry and Psychotherapy, University Medical Center Hamburg-Eppendorf, Germany \\ ${ }^{4}$ Departments of Psychiatry and Radiology, Harvard Medical School, Boston, MA \\ ${ }^{5}$ Department of Radiology, Faculty of Medicine, Ludwig-Maximilians-Universität, Munich, \\ Germany \\ ${ }^{6}$ Clinical Neuroscience Division, Laboratory of Neuroscience, Veterans Affairs Boston Healthcare \\ System, Brockton Division, Brockton, MA \\ ${ }^{7}$ Department of Psychiatry, University Hospital and Faculty of Medicine, Martin-Luther-Universität \\ Halle-Wittenberg, Germany
}

\begin{abstract}
CNTNAP2 is a gene on chromosome 7 that has shown associations with autism and schizophrenia, and there is evidence that it plays an important role for neuronal synchronization and brain connectivity. In this study, we assessed the relationship between Diffusion Tensor Imaging (DTI), a putative marker of anatomical brain connectivity, and multiple single nucleotide polymorphisms (SNPs) spread out over this large gene. 81 healthy controls and 44 patients with schizophrenia (all Caucasian) underwent DTI and genotyping of 31 SNPs within CNTNAP2. We employed Tract-based Spatial Statistics (TBSS) for inter-subject brain registration and computed average diffusivity values for six major white matter tracts. Analyses of Covariance (ANCOVAs) were computed to test for possible associations with genotypes. The strongest association, which survived rigorous Bonferroni correction, was between rs2710126 genotype and Fractional Anisotropy (FA) in the uncinate fasciculus ( $\mathrm{p}=.00003)$. This anatomical location is particularly interesting given the enriched fronto-temporal expression of $C N T N A P 2$ in the developing brain. For this SNP, no phenotype association has been reported before. There were several further genotype-DTI associations that were nominally significant but did not survive Bonferroni
\end{abstract}

() 2013 Elsevier Ltd. All rights reserved.

Correspondence to Christian Clemm von Hohenberg, Psychiatry Neuroimaging Laboratory, Brigham and Women's Hospital and Harvard Medical School, 1249 Boylston St., Boston, MA 02215, Tel. +1 617 525-6105, Fax +1 617 525-6150, clemm@bwh.harvard.edu.

Publisher's Disclaimer: This is a PDF file of an unedited manuscript that has been accepted for publication. As a service to our customers we are providing this early version of the manuscript. The manuscript will undergo copyediting, typesetting, and review of the resulting proof before it is published in its final citable form. Please note that during the production process errors may be discovered which could affect the content, and all legal disclaimers that apply to the journal pertain. 
correction, including an association between axial diffusivity in the dorsal cingulum bundle and a region in intron 13 (represented by rs2710102, rs759178, rs2538991), which has previously been reported to be associated with anterior-posterior functional connectivity. We present new evidence about the effects of $C N T N A P 2$ on brain connectivity, whose disruption has been hypothesized to be central to schizophrenia pathophysiology.

\section{Keywords}

Caspr2; genetics; endophenotype; magnetic resonance imaging; schizophrenia; autism

\section{Introduction}

Schizophrenia is hypothesized to be a disorder of brain connectivity (Friston \& Frith, 1995; Stephan et al., 2009), which could be closely related to abnormalities in the brain's white matter tracts (Konrad \& Winterer, 2008). Microstructure of these tracts is widely investigated using DTI, and a large body of evidence supports abnormalities in schizophrenia (Fitzsimmons et al., 2013; Kyriakopoulos \& Frangou, 2009; Mueller et al., 2011). On the other hand, the anatomical localization of these findings has not been consistent, and it is widely acknowledged that schizophrenia is a heterogeneous disease. This may also explain why it has been very difficult to find genetic loci consistently associated with the disorder, even though schizophrenia is highly heritable (Cardno et al., 1999). To address these challenges and to learn more about the mechanisms underlying the disease, the study of intermediate phenotypes (often called endophenotypes, (Braff \& Light, 2005)) has come into focus as a worthwhile approach: these are heritable and measurable traits that are hypothesized to represent an intermediate in the causal chain from the genotype to complex and heterogeneous phenotypes like mental disorders. Since the putative causal relationship between the gene and the intermediate phenotype is assumed to be closer than between the gene and the disorder, statistical correlations should also be stronger. Increasingly in recent years, DTI indices have been studied as potential intermediate phenotypes (e.g. (Dennis et al., 2011; McIntosh et al., 2008; Tan et al., 2010; Winterer et al., 2008)).

Contactin-associated protein-like 2 (CNTNAP2), also known as NRXN4 (Neurexin 4), spans $2.3 \mathrm{Mb}$ on Chromosome 7, and hence is one of the largest genes in the human genome. It has been linked to different neuropsychiatric phenotypes, most notably autism (Alarcon et al., 2002; Arking et al., 2008; Bakkaloglu et al., 2008; Jackman et al., 2009; Li et al., 2010; Rossi et al., 2008). Several studies also point to a role in schizophrenia, where both rare (Friedman et al., 2008; Stone et al., 2008) and common (O'Dushlaine et al., 2011; Wang et al., 2010) genetic variants have been implicated, also in a genome-wide analysis (Wang et al., 2010).

Several lines of evidence support a role of CNTNAP2 for brain connectivity. Firstly, there is a small body of imaging genetics literature (Dennis et al., 2011; Scott-Van Zeeland et al., 2010; Tan et al., 2010; Whalley et al., 2011). Specifically, in children carrying the autism risk allele (C) of rs2710102, prefrontal cortex shows reduced long-range (anterior-posterior), but increased short-range functional connectivity (Scott-Van Zeeland et al., 2010). In a recent DTI study (Dennis et al., 2011), whole-brain tractography and graph metrics were used to compare indices of structural connectivity between genotypes of rs2710102. Amongst others, $\mathrm{C}$ homozygotes had smaller "eccentricity", which is the distance of a given node to the farthest other node to which it is connected (although it should be noted that these network distances do not simply correspond to anatomical distances). This and the 
fMRI study cited above (Scott-Van Zeeland et al., 2010) provide some preliminary evidence that the $\mathrm{C}$ allele of rs 2710102 is associated with reduced long-range brain connectivity.

Another study, comparing genotypes of rs 7794745 , found that $\mathrm{T}$ homozygotes showed reductions of grey- and white-matter volumes in cerebellar, frontal and occipital areas and their connecting tracts, and there were gender-specific FA decreases (anterior thalamic radiation in females; inferior fronto-occipital fasciculus in males) (Tan et al., 2010).

Further evidence for the gene's influence on brain connectivity comes from its cellular functions: $C N T N A P 2$ codes for Caspr2, which is a transmembrane protein located at the juxtaparanode in myelinated axons, where it is responsible for spatial clustering of voltagegated potassium channels Kv1.1 and Kv1.2 (Poliak et al., 1999). (In myelinated axons, each node of Ranvier is symmetrically surrounded by two paranodal regions and, beyond these, so-called juxtaparanodes.)

In a similar way, Caspr2 acts at the distal portion of the axon initial segment (AIS) (Inda et al., 2006). It is this distal portion where so-called chandelier cells, which belong to the parvalbuminexpressing (PV) class of interneurons (Rudy et al., 2011), have their synapses (Inda et al., 2006). In schizophrenia, both the AIS and PV interneurons are specifically affected (Braun et al., 2007; Lewis, 2011; Rujescu et al., 2006). PV interneurons are also specifically diminished in CNTNAP2 knock-out mice (Penagarikano et al., 2011). Since interneurons play an important role in synchronizing of neuronal activity (Cobb et al., 1995), it may not be surprising that these knockout mice also showed reduced synchrony of neuronal activity, while overall rate and amplitude of firing were unchanged (Penagarikano et al., 2011).

Synchronized neuronal activity in turn is important for the formation and maintenance of synapses and axons (Zhang \& Poo, 2001). More generally, altered functional connectivity can be expected to lead to altered structural connectivity (Hua \& Smith, 2004; Stephan et al., 2009; Zhang et al., 2001).

Accordingly, in the present study, we sought to test the hypothesis that CNTNAP2 polymorphisms are associated with structural connectivity as assessed with DTI. In order to localize any genotype effects within this unusually large gene, we chose 31 SNPs spread out over the whole gene, including loci that have been found to be associated with clinical, neuropsychological (especially language-related) and imaging phenotypes (see Table 1).

\section{Methods}

\section{Subjects}

This study was part of a larger clinical, imaging and genetics study at the Department of Psychiatry, University of Munich, Germany. Patients with schizophrenia were recruited in inpatient, day-treatment and outpatient settings, and DSM-IV diagnosis of schizophrenia was confirmed by clinical interview with an experienced psychiatrist. Unrelated healthy volunteers were recruited from the general community and underwent comprehensive interviews including the Structured Clinical Interview for DSM-IV (SCID I and SCID II (First et al., 1997; Wittchen et al., 1997)), to assess for any lifetime axis I and II disorders. In order to avoid ethnicity as a confounding factor in the genetic analysis, only Caucasian individuals were included in this study.

Exclusion criteria for all participants were neurological disorders, history of traumatic brain injury, medical illness significantly impairing neurocognitive function and diagnosis of mental retardation (as determined by WRAT- 4 and/or WASI scores $<70$ ). Additional 
exclusion criteria for control subjects were presence or history of any mental illness in the volunteers themselves or their first degree relatives.

The study was conducted in accordance with the Declaration of Helsinki and was approved by the local Ethics Committee at the University of Munich, Faculty of Medicine. Written informed consent was obtained from all participants after explaining the experimental procedures. All patients included were capable of giving fully informed consent, as determined by a psychiatrist.

\section{Genotyping}

SNPs were selected from the NCBI SNP database (http://www.ncbi.nlm.nih.gov/entrez/ query.fcgi? $\mathrm{db}=\mathrm{snp}$ ). In a first step, we prioritized SNPs that are exonic. Of the 153 exonic CNTNAP2 SNPs listed in the database, however, only two are polymorphic in Caucasian populations (i.e. have a minor allele frequency of $>1 \%$ ). These two were selected.

In a second step, to include additional SNPs, we selected those with phenotype associations previously reported in pubmed publications (http://www.ncbi.nlm.nih.gov/entrez/query.fcgi? $\mathrm{db}=$ PubMed), prioritizing associations with neuropsychiatric phenotypes (see Table 1).

Thirdly, we included haplotype tagging SNPs (i.e., a SNP that is representative of a region with high linkage disequilibrium (LD)). These were selected using the "Tagger" algorithm (http://www.broad.mit.edu/mpg/tagger/server.html), which is described in detail elsewhere (de Bakker et al., 2005). The rationale is to cover as much genetic variability in CNTNAP2 as possible with as few SNPs as possible.

Fourthly, large physical gaps were covered through inclusion of further SNPs. Lastly, some SNPs had to be excluded due to incompatibilities between SNPs in the multiplex sequencing assay, for example incompatibilities between the relevant primers. In these cases, we substituted the SNP with another one in high LD with the first.

Altogether, 31 SNPs were included covering $\sim 2.29 \mathrm{Mb}$ of the CNTNAP2 gene region (Chr7: 145810125 ... 148103987 position, hg19 assembly) with a mean difference of $73 \mathrm{kp}$ between the SNPs (see Table 1).

For genotyping, DNA was extracted from blood samples and SNPs were genotyped using the MassARRAY platform (Sequenom, San Diego, CA) according to manufacturer's protocol (Oeth et al., 2007). Briefly, PCR- and extension primers were designed using the Assay Designer 4.0 (Sequenom, San Diego, CA). 12.5ng of genomic DNA were used for Multiplex PCR reactions with a mastermix containing 500 $\mu \mathrm{M}$ dNTPs (ABgene, Hamburg, Germany), 100nM PCR primers, $1.625 \mathrm{mM} \mathrm{MgCl} 2$ and $0.5 \mathrm{U}$ HotStar Taq polymerase (Qiagen, Hilden, Germany). Following an SAP (shrimp alkaline phosphatase) treatment, the iPLEX reaction cocktail containing extension primers $(7-14 \mu \mathrm{M}), 1 \times$ iPLEX termination mix and $1 \times$ iPLEX enzyme (Sequenom, San Diego, CA) was added to the PCR-products. After desalting the extension products with SpectroCLEAN resin (sequenom, San Diego, CA), samples were spotted on SpecroCHIPs GenII (Sequenom, San Diego, CA) and analyzed with the MassARRAY MALDI-TOF mass spectrometer. Allele-specific extension products and resulting genotypes were identified by Typer 3.4 Software (Sequenom, San Diego, CA). For genotyping quality assurance the CEU HapMap Trios (Coriell Institute for Medical research, Camden, NJ) were included and compared with the hapmap database (www.hapmap.org).

All selected SNPs met the following criteria: minor allele frequency was $>1 \%$, genotyping information was available for at least $90 \%$ of study subjects (mean: $97.3 \%$ ), and p-value for 
deviation from Hardy-Weinberg equilibrium was greater than .01. Supplemental Figure S1 gives a graphical representation of the genomic locations and LDs of all 31 SNPs.

\section{Image acquisition}

All participants were scanned on the same 1.5 Tesla MRI scanner (Sonata, Siemens Medical Solutions, Erlangen, Germany) using a standard circular-polarized head coil. Brain Diffusion Tensor MRI (DTI) was acquired in axial orientation using a diffusion-weighted spin-echo single-shot echo-planar imaging (EPI) sequence with diffusion encoding in 32 directions $(\mathrm{TE}=83 \mathrm{~ms}, \mathrm{TR}=6600 \mathrm{~ms}, \mathrm{FOV}=320 \times 280$, matrix size $128 \times 112,44$ contiguous axial slices with $2.5 \mathrm{~mm}$ thickness, b-values 0 and $1000 \mathrm{~s} / \mathrm{mm}^{2}$ ). MRI scans were carefully evaluated to rule out structural abnormalities or artifacts.

\section{Image processing}

First, the diffusion data were corrected for motion and eddy currents through affine registration to the b0 volume. This was done using the Linear Image Registration Tool (FLIRT), part of the Oxford Centre for Functional MRI of the Brain (FMRIB) Software Library (FSL, http://fsl.fmrib.ox.ac.uk/fsl/). Diffusion gradients were rotated accordingly.

After deleting non-brain tissue from the images using the Brain Extraction Tool (BET) (Smith, 2002), the diffusion tensor was estimated for each voxel, using a weighted leastsquares method in 3D Slicer (http://www.slicer.org). The diffusion tensor consists of three Cartesian eigenvectors with corresponding eigenvalues, $\left(\lambda_{1}, \lambda_{2}, \lambda_{3}\right.$, in order of decreasing magnitude), quantifying water movement in three perpendicular directions. In white matter tracts, water is thought to move more freely along the axons than in perpendicular directions. Such directionality is quantified by FA, the normalized variance of the three eigenvalues. Mean diffusivity (MD) is the average of all three eigenvalues and thus quantifies overall diffusion regardless of direction. Axial diffusivity $\left(\mathrm{AD}=\lambda_{1}\right)$ measures diffusion in the principal diffusion direction (e.g. along the axon), while radial diffusivity $\left(\mathrm{RD}=\left(\lambda_{2}+\lambda_{3}\right) / 2\right)$ reflects diffusion perpendicular to this main direction.

For between-subject registration, we used TBSS, also part of FSL (Smith et al., 2006). TBSS creates a white-matter skeleton representing the central course of fiber tracts and therefore reduces partial volume effects. First, all FA images were non-linearly registered to the FMRIB58_FA template using the Non-Linear Image Registration Tool in FSL (FNIRT) (Andersson et al., 2007a; b), using a b-spline representation of the registration warp field (Rueckert et al., 1999). Next, a mean FA volume was computed and subsequently underwent a thinning process to create the skeleton, which was then thresholded to contain only voxels with FA>0.2. Along this skeleton, neighboring voxels were searched for the local maximum FA values, which were then projected onto the skeleton. In order to analyze the other scalars of interest (AD, RD and MD), we applied the nonlinear warps obtained from FA registration, as well as the skeleton projection of the FA data, to the other diffusion scalar volumes.

For part of the scans, the field-of-view did not contain parts of the cerebellum and the inferior temporal lobe. After TBSS processing, all registered FA volumes (and the mean FA volume) contained only that field-of-view that was common to all subjects included in the study. Within this common field-of-view, co-registration of white matter tracts was undisturbed. For analysis, we only chose white-matter tracts whose atlas mask was entirely inside this common field-of-view (see below).

Johns Hopkins University (JHU) ICBM-DTI-81 White-Matter Labels Atlas (Hua et al., 2008; Mori, 2005) was used to mask the relevant parts of the white-matter skeleton, which is similar to a method previously described by other groups (Karlsgodt et al., 2009; Karlsgodt 
et al., 2008; Kochunov et al., 2010). This atlas contains labels for 27 white matter regions. To reduce the number of tests, we focused our analyses on six major cortico-cortical white matter tracts (see Figure 1): cingulum bundle (cingulate gyrus part), corpus callosum (genu, body and splenium), superior longitudinal fasciculus, anterior thalamic radiation (comprising the atlas labels "anterior limb of internal capsule" and "anterior corona radiata"), sagittal stratum (which according to the JHU atlas contains fibers from the inferior longitudinal and inferior fronto-occipital fasciculi), and uncinate fasciculus.

The TBSS skeleton was masked with the appropriate atlas labels, and mean values of FA, $\mathrm{MD}, \mathrm{AD}$ and $\mathrm{RD}$ were computed over every masked region.

\section{Statistical Analysis}

For each tract, correlation between FA values in the two hemispheres was high (Pearson's $r$ $>.65$ ), so we decided to average diffusivity values over both hemispheres for the subsequent analyses. This was done in order to reduce the number of repeated measures, and to include the corpus callosum, which is unpaired, into the same statistical model. (An additional model with separate entries for left and right was computed as a secondary analysis, see below.)

In the main analysis, we computed a mixed ANCOVA for each SNP: within-subject factor was region (6 levels), between-subjects factor was genotype, and covariates were diagnostic group, gender and age. If there was a significant main effect of genotype, this was noted. If there was a significant genotype-by-region interaction, this meant that the genotype effect differed between brain regions.

Only in this latter case, we computed separate ANCOVAs for each of the six regions. In these region-specific ANCOVAs, between-subjects factor was genotype, and covariates were diagnostic group, gender and age.

A Bonferroni correction was performed as follows: In the first model (mixed ANCOVAs), since we tested 31 SNPs and 4 diffusivity parameters, the significance threshold was set to . $05 /(31 * 4)=.0004$. In the second model (region-specific ANCOVAs), the threshold was set to $.05 /(31 * 4 * 6)=.000067$, since the theoretical maximum number of tests could have been 31 regions times 4 DTI indices times 6 regions.

We consider this approach to be conservative for several reasons: Firstly, we computed the region-specific ANCOVAs only if there was a significant genotype-by-region interaction in the mixed ANCOVA. Therefore, we computed only a fraction of those $744(31 * 4 * 6)$ regionspecific ANCOVAs that would have theoretically been possible. Secondly, the 31 SNPs are in partial Linkage Disequilibrium and are therefore not statistically independent from each other. Thirdly, also the four DTI indices are very closely related mathematically, and therefore cannot be considered statistically independent either.

All statistical analyses were performed using SPSS for Mac, Version 19.

\section{Results}

\section{Demographical and clinical variables}

125 subjects (44 patients with schizophrenia and 81 healthy controls) were included. See Table 2 for demographical and clinical information.

The primary objective of this study was to compare diffusivity values between genotype groups. We therefore assessed whether genotype groups for all 31 SNPs differed on any of 
the following (potentially confounding) variables: diagnosis, age, gender, handedness, level of education and, for schizophrenics only, chlorpromazine equivalents and PANSS scores and sub-scores. This was assessed with one-way ANOVAs, Kruskal-Wallis-Tests or $X^{2}$-tests as appropriate. As an important result, the SNP whose significant effect on FA is reported below was not associated with any of these variables.

Since a secondary objective in our study was to compare genotype-diffusivity associations between patients and controls (i.e. test for genotype-by-diagnosis interaction effects), we also assessed whether patients and controls differed on demographic variables. This was the case for age and gender, but not handedness and level of education (see Table 2). Age and gender were therefore included as covariates in all further analyses.

\section{Genotype effects on diffusivity measures}

We found a significant genotype-by-region interaction effect on FA for rs 2710126 ( $F(8.128$, 483.6) $=4.108$, degrees of freedom adjusted according to Huyn-Feldt to account for violated assumption of sphericity, $\mathrm{p}=.00008$ ).

In order to follow up on this interaction, we performed ANCOVAs for each of the six regions separately. There was a significant main effect of rs2710126 genotype on FA in the uncinate fasciculus (UF, see Figure 2 and Table 3). Genotype explained $15 \%$ of the total variance in FA $\left(\eta^{2}=.15\right)$, corresponding to a medium to large effect size. Post-hoc contrasts indicated that A homozygotes had lower FA than both other groups.

For RD, there were corresponding effects (A homozygotes showing higher RD than the rest), which did not survive Bonferroni correction (see Supplementary Table S1). There were no effects for MD or $\mathrm{AD}$.

In addition, we assessed whether the effect of rs2710126 on FA in the UF was present also within each subsample (patients and controls). In either subgroup, the effect was still nominally significant, but did not survive Bonferroni correction (controls: $\mathrm{p}=.0006$, patients: $\mathrm{p}=.03)$.

Further, we examined whether the effect of rs 2710126 on FA in the UF was different between patients and controls. To this end, we computed a General Linear Model modified relative to our main analysis, namely including a genotype-by-diagnosis interaction term. This interaction was non-significant, suggesting that the genotype effect does not fundamentally differ between patients and controls.

Also, in order to test whether the effect of genotype on FA in the UF was side-specific, we computed a model with separate entries for each hemisphere, with "hemisphere" as a withinsubjects factor. There was no significant side-by-genotype interaction effect, suggesting that the genotype effect cannot be assumed to be side-specific.

Apart from rs2710126, there were several further SNPs that were nominally significant with $\mathrm{p}<.01$, but did not survive Bonferroni correction (see Supplementary Table S1 and Discussion).

\section{Discussion}

To the best of our knowledge, this is the first imaging genetics study to assess the effect of multiple loci spread out over the whole CNTNAP2 gene, which is one of the largest genes in the human genome and has previously shown numerous associations with neuropsychiatric phenotypes. 
In our sample, rs2710126 A homozygotes had lower FA specifically in the UF. This association survived rigorous Bonferroni correction for 31 SNPs, 6 white matter regions and 4 DTI indices. The anatomical specificity may correspond to gene expression data in human fetal development: The UF is one of the main pathways connecting the frontal and anterior temporal lobes, and CNTNAP2 expression was repeatedly found to be enriched in frontal and anterior temporal cortices (Abrahams et al., 2007; Alarcon et al., 2008; Ip et al., 2010). In schizophrenia, abnormal DTI measures in the uncinate fasciculus have repeatedly been found (Fitzsimmons et al., 2013), and correlate with neuropsychological functioning (Hanlon et al., 2012; Spoletini et al., 2009). Fronto-temporal dysconnection (particularly between dorsolateral prefrontal cortex and hippocampus) has been hypothesized to be a core factor in the pathophysiology of schizophrenia (Meyer-Lindenberg, 2010).

When including a genotype-by-diagnosis interaction term into the statistical model, we found no evidence that the genotype-DTI association was different between patients and controls. Given the smaller size of the patient sample, we acknowledge that larger studies are needed to investigate this interaction more closely.

Several other SNPs had nominally significant effects that did not, however, survive Bonferroni correction (see Supplemental Table S1). In particular, it might be worth noting the associations of a region around intron 13 (represented by rs2710102, rs759178 and rs2538991). This region has previously shown numerous associations with imaging and neuropsychological (especially language-related) phenotypes (see Table 1), and therefore represents an interesting a-priori candidate. In our sample, there was an effect on AD in the dorsal cingulum bundle. Anatomically, this may be related to the association of rs 2710102 with functional connectivity between medial prefrontal cortex and posterior brain regions (Scott-Van Zeeland et al., 2010).

With regard to the histological interpretation of our findings, axonal and myelin alterations are often referred to as possible correlates of decreased FA (Concha et al., 2010; Harsan et al., 2006; Klawiter et al., 2011; Song et al., 2003). It should be noted in this context that CNTNAP2 knockout mice did not show alterations in myelin morphology or thickness, nor in axonal caliber, at least in optic nerves (Poliak et al., 2003).

In light of the $C N T N A P 2$ functions mentioned in the Introduction (particularly concerning neuronal synchronization), and given the gene's importance for neurodevelopment (Abrahams et al., 2007; Alarcon et al., 2008; Penagarikano et al., 2011; Poliak et al., 1999; Strauss et al., 2006; Whitehouse et al., 2011), one could speculate that, on the basis of functional connectivity differences, development of long-range anatomical connectivity may vary between CNTNAP2 genotypes (Hua et al., 2004; Stephan et al., 2009; Zhang et al., 2001).

Another histological dimension that could potentially underly our findings are ectopic neurons present in white matter, which have been linked both to CNTNAP2 dysfunction (Penagarikano et al., 2011; Strauss et al., 2006) and schizophrenia (Eastwood \& Harrison, 2003; Rioux et al., 2003).

These interpretations, however, remain speculative, and it is important to note that a SNP represents genetic variation in a haplotype block, not altered gene function. Our findings thus provide only indirect evidence for a causal chain from the polymorphism via gene function to altered white matter microstructure.

Additional limitations of this study include the fact that the sample size was not sufficient to confirm the genotype effect in both subgroups individually, at the chosen level of Bonferroni correction. Moreover, in face of the extremely complex causal network between 
multiple genotypes, environmental factors, intermediate phenotypes and disease phenotypes, our study only assesses a fraction of possible associations and interactions.

In summary, we detected some interesting intermediate phenotype associations. Specifically, the effect of rs2710126 on UF diffusivity is an intriguing finding given the anatomical expression pattern of the gene in the developing human brain. Further, there was evidence of an association within a genetic region (intron 13) that has already been implicated in numerous neuropsychiatric phenotypes.

Since we chose a relatively large number of SNPs spread out over this unusually large gene, our study should contain interesting information as to which regions of CNTNAP2 are particularly relevant for brain connectivity and functioning in health and disease.

\section{Supplementary Material}

Refer to Web version on PubMed Central for supplementary material.

\section{References}

Abrahams BS, Tentler D, Perederiy JV, Oldham MC, Coppola G, Geschwind DH. Genome-wide analyses of human perisylvian cerebral cortical patterning. Proc Natl Acad Sci U S A. 2007; 104:17849-17854. [PubMed: 17978184]

Alarcon M, Abrahams BS, Stone JL, Duvall JA, Perederiy JV, Bomar JM, Sebat J, Wigler M, Martin CL, Ledbetter DH, Nelson SF, Cantor RM, Geschwind DH. Linkage, association, and geneexpression analyses identify CNTNAP2 as an autism-susceptibility gene. Am J Hum Genet. 2008; 82:150-159. [PubMed: 18179893]

Alarcon M, Cantor RM, Liu J, Gilliam TC, Geschwind DH. Evidence for a language quantitative trait locus on chromosome 7q in multiplex autism families. Am J Hum Genet. 2002; 70:60-71. [PubMed: 11741194]

Andersson, JLR.; Jenkinson, M.; Smith, S. Non-linear optimisation. 2007a. FMRIB technical report TR07JA1 from www.fmrib.ox.ac.uk/analysis/techrep

Andersson, JLR.; Jenkinson, M.; Smith, S. Non-linear registration, aka Spatial normalisation. 2007b. FMRIB technical report TR07JA2 from www.fmrib.ox.ac.uk/analysis/techrep

Arking DE, Cutler DJ, Brune CW, Teslovich TM, West K, Ikeda M, Rea A, Guy M, Lin S, Cook EH, Chakravarti A. A common genetic variant in the neurexin superfamily member CNTNAP2 increases familial risk of autism. Am J Hum Genet. 2008; 82:160-164. [PubMed: 18179894]

Bakkaloglu B, O'Roak BJ, Louvi A, Gupta AR, Abelson JF, Morgan TM, Chawarska K, Klin A, Ercan-Sencicek AG, Stillman AA, Tanriover G, Abrahams BS, Duvall JA, Robbins EM, Geschwind DH, Biederer T, Gunel M, Lifton RP, State MW. Molecular cytogenetic analysis and resequencing of contactin associated protein-like 2 in autism spectrum disorders. Am J Hum Genet. 2008; 82:165-173. [PubMed: 18179895]

Braff DL, Light GA. The use of neurophysiological endophenotypes to understand the genetic basis of schizophrenia. Dialogues Clin Neurosci. 2005; 7:125-135. [PubMed: 16262208]

Braun I, Genius J, Grunze H, Bender A, Moller HJ, Rujescu D. Alterations of hippocampal and prefrontal GABAergic interneurons in an animal model of psychosis induced by NMDA receptor antagonism. Schizophr Res. 2007; 97:254-263. [PubMed: 17601703]

Cardno AG, Marshall EJ, Coid B, Macdonald AM, Ribchester TR, Davies NJ, Venturi P, Jones LA, Lewis SW, Sham PC, Gottesman II, Farmer AE, McGuffin P, Reveley AM, Murray RM. Heritability estimates for psychotic disorders: the Maudsley twin psychosis series. Arch Gen Psychiatry. 1999; 56:162-168. [PubMed: 10025441]

Cobb SR, Buhl EH, Halasy K, Paulsen O, Somogyi P. Synchronization of neuronal activity in hippocampus by individual GABAergic interneurons. Nature. 1995; 378:75-78. [PubMed: 7477292] 
Concha L, Livy DJ, Beaulieu C, Wheatley BM, Gross DW. In vivo diffusion tensor imaging and histopathology of the fimbria-fornix in temporal lobe epilepsy. J Neurosci. 2010; 30:996-1002. [PubMed: 20089908]

de Bakker PI, Yelensky R, Pe'er I, Gabriel SB, Daly MJ, Altshuler D. Efficiency and power in genetic association studies. Nat Genet. 2005; 37:1217-1223. [PubMed: 16244653]

Dennis EL, Jahanshad N, Rudie JD, Brown JA, Johnson K, McMahon KL, de Zubicaray GI, Montgomery G, Martin NG, Wright MJ, Bookheimer SY, Dapretto M, Toga AW, Thompson PM. Altered structural brain connectivity in healthy carriers of the autism risk gene, CNTNAP2. Brain Connect. 2011; 1:447-459. [PubMed: 22500773]

Eastwood SL, Harrison PJ. Interstitial white matter neurons express less reelin and are abnormally distributed in schizophrenia: towards an integration of molecular and morphologic aspects of the neurodevelopmental hypothesis. Mol Psychiatry. 2003; 8(769):821-731.

First, MB.; Spitzer, RL.; Gibbon, M.; Williams, JBW. Structured Clinical Interview for DSM-IV Axis I Disorders-Clinician Version (SCID-IV). Washington, DC: American Psychiatric Press; 1997.

Fitzsimmons J, Kubicki M, Shenton ME. Review of functional and anatomical brain connectivity findings in schizophrenia. Curr Opin Psychiatry. 2013; 26:172-187. [PubMed: 23324948]

Friedman JI, Vrijenhoek T, Markx S, Janssen IM, van der Vliet WA, Faas BH, Knoers NV, Cahn W, Kahn RS, Edelmann L, Davis KL, Silverman JM, Brunner HG, van Kessel AG, Wijmenga C, Ophoff RA, Veltman JA. CNTNAP2 gene dosage variation is associated with schizophrenia and epilepsy. Mol Psychiatry. 2008; 13:261-266. [PubMed: 17646849]

Friston KJ, Frith CD. Schizophrenia: a disconnection syndrome? Clin Neurosci. 1995; 3:89-97. [PubMed: 7583624]

Hanlon FM, Houck JM, Klimaj SD, Caprihan A, Mayer AR, Weisend MP, Bustillo JR, Hamilton DA, Tesche CD. Frontotemporal anatomical connectivity and working-relational memory performance predict everyday functioning in schizophrenia. Psychophysiology. 2012; 49:1340-1352. [PubMed: 22882287]

Harsan LA, Poulet P, Guignard B, Steibel J, Parizel N, de Sousa PL, Boehm N, Grucker D, Ghandour MS. Brain dysmyelination and recovery assessment by noninvasive in vivo diffusion tensor magnetic resonance imaging. J Neurosci Res. 2006; 83:392-402. [PubMed: 16397901]

Hua JY, Smith SJ. Neural activity and the dynamics of central nervous system development. Nat Neurosci. 2004; 7:327-332. [PubMed: 15048120]

Hua K, Zhang J, Wakana S, Jiang H, Li X, Reich DS, Calabresi PA, Pekar JJ, van Zijl PC, Mori S. Tract probability maps in stereotaxic spaces: analyses of white matter anatomy and tract-specific quantification. Neuroimage. 2008; 39:336-347. [PubMed: 17931890]

Inda MC, DeFelipe J, Munoz A. Voltage-gated ion channels in the axon initial segment of human cortical pyramidal cells and their relationship with chandelier cells. Proc Natl Acad Sci U S A. 2006; 103:2920-2925. [PubMed: 16473933]

Ip BK, Wappler I, Peters H, Lindsay S, Clowry GJ, Bayatti N. Investigating gradients of gene expression involved in early human cortical development. J Anat. 2010; 217:300-311. [PubMed: 20579172]

Jackman C, Horn ND, Molleston JP, Sokol DK. Gene associated with seizures, autism, and hepatomegaly in an Amish girl. Pediatr Neurol. 2009; 40:310-313. [PubMed: 19302947]

Karlsgodt KH, Niendam TA, Bearden CE, Cannon TD. White matter integrity and prediction of social and role functioning in subjects at ultra-high risk for psychosis. Biol Psychiatry. 2009; 66:562569. [PubMed: 19423081]

Karlsgodt KH, van Erp TG, Poldrack RA, Bearden CE, Nuechterlein KH, Cannon TD. Diffusion tensor imaging of the superior longitudinal fasciculus and working memory in recent-onset schizophrenia. Biol Psychiatry. 2008; 63:512-518. [PubMed: 17720147]

Klawiter EC, Schmidt RE, Trinkaus K, Liang HF, Budde MD, Naismith RT, Song SK, Cross AH, Benzinger TL. Radial diffusivity predicts demyelination in ex vivo multiple sclerosis spinal cords. Neuroimage. 2011; 55:1454-1460. [PubMed: 21238597]

Kochunov P, Glahn DC, Lancaster JL, Winkler AM, Smith S, Thompson PM, Almasy L, Duggirala R, Fox PT, Blangero J. Genetics of microstructure of cerebral white matter using diffusion tensor imaging. Neuroimage. 2010; 53:1109-1116. [PubMed: 20117221] 
Konrad A, Winterer G. Disturbed structural connectivity in schizophrenia primary factor in pathology or epiphenomenon? Schizophr Bull. 2008; 34:72-92. [PubMed: 17485733]

Kyriakopoulos M, Frangou S. Recent diffusion tensor imaging findings in early stages of schizophrenia. Curr Opin Psychiatry. 2009; 22:168-176. [PubMed: 19553871]

Lewis DA. The chandelier neuron in schizophrenia. Dev Neurobiol. 2011; 71:118-127. [PubMed: 21154915]

Li X, Hu Z, He Y, Xiong Z, Long Z, Peng Y, Bu F, Ling J, Xun G, Mo X, Pan Q, Zhao J, Xia K. Association analysis of CNTNAP2 polymorphisms with autism in the Chinese Han population. Psychiatr Genet. 2010; 20:113-117. [PubMed: 20414140]

McIntosh AM, Moorhead TW, Job D, Lymer GK, Munoz Maniega S, McKirdy J, Sussmann JE, Baig BJ, Bastin ME, Porteous D, Evans KL, Johnstone EC, Lawrie SM, Hall J. The effects of a neuregulin 1 variant on white matter density and integrity. Mol Psychiatry. 2008; 13:1054-1059. [PubMed: 17925794]

Meyer-Lindenberg A. From maps to mechanisms through neuroimaging of schizophrenia. Nature. 2010; 468:194-202. [PubMed: 21068827]

Mori, S. MRI Atlas of Human White Matter. Elsevier; 2005.

Mueller S, Keeser D, Reiser MF, Teipel S, Meindl T. Functional and Structural MR Imaging in Neuropsychiatric Disorders, Part 2: Application in Schizophrenia and Autism. AJNR Am J Neuroradiol. 2011

Newbury DF, Paracchini S, Scerri TS, Winchester L, Addis L, Richardson AJ, Walter J, Stein JF, Talcott JB, Monaco AP. Investigation of dyslexia and SLI risk variants in reading- and languageimpaired subjects. Behav Genet. 2011; 41:90-104. [PubMed: 21165691]

O'Dushlaine C, Kenny E, Heron E, Donohoe G, Gill M, Morris D, Corvin A. Molecular pathways involved in neuronal cell adhesion and membrane scaffolding contribute to schizophrenia and bipolar disorder susceptibility. Mol Psychiatry. 2011; 16:286-292. [PubMed: 20157312]

Oeth P, Beaulieu M, Park P, Kosman D, del Mistro G, van den Boom D, Jurinke C. iPLEX ${ }^{\mathrm{TM}}$ Assay Increased: Plexing Efficiency and Flexibility for MassARRAY® System Through Single Base Primer Extension with Mass-Modified Terminators. Sequenom application note. 2007

Penagarikano O, Abrahams BS, Herman EI, Winden KD, Gdalyahu A, Dong H, Sonnenblick LI, Gruver R, Almajano J, Bragin A, Golshani P, Trachtenberg JT, Peles E, Geschwind DH. Absence of CNTNAP2 leads to epilepsy, neuronal migration abnormalities, and core autism-related deficits. Cell. 2011; 147:235-246. [PubMed: 21962519]

Peter B, Raskind WH, Matsushita M, Lisowski M, Vu T, Berninger VW, Wijsman EM, Brkanac Z. Replication of CNTNAP2 association with nonword repetition and support for FOXP2 association with timed reading and motor activities in a dyslexia family sample. J Neurodev Disord. 2011; 3:39-49. [PubMed: 21484596]

Poliak S, Gollan L, Martinez R, Custer A, Einheber S, Salzer JL, Trimmer JS, Shrager P, Peles E. Caspr2, a new member of the neurexin superfamily, is localized at the juxtaparanodes of myelinated axons and associates with K+ channels. Neuron. 1999; 24:1037-1047. [PubMed: 10624965]

Poliak S, Salomon D, Elhanany H, Sabanay H, Kiernan B, Pevny L, Stewart CL, Xu X, Chiu SY, Shrager P, Furley AJ, Peles E. Juxtaparanodal clustering of Shaker-like K+ channels in myelinated axons depends on Caspr2 and TAG-1. J Cell Biol. 2003; 162:1149-1160. [PubMed: 12963709]

Rioux L, Nissanov J, Lauber K, Bilker WB, Arnold SE. Distribution of microtubule-associated protein MAP2-immunoreactive interstitial neurons in the parahippocampal white matter in subjects with schizophrenia. Am J Psychiatry. 2003; 160:149-155. [PubMed: 12505814]

Rossi E, Verri AP, Patricelli MG, Destefani V, Ricca I, Vetro A, Ciccone R, Giorda R, Toniolo D, Maraschio P, Zuffardi O. A 12Mb deletion at 7q33-q35 associated with autism spectrum disorders and primary amenorrhea. Eur J Med Genet. 2008; 51:631-638. [PubMed: 18675947]

Rudy B, Fishell G, Lee S, Hjerling-Leffler J. Three groups of interneurons account for nearly $100 \%$ of neocortical GABAergic neurons. Dev Neurobiol. 2011; 71:45-61. [PubMed: 21154909]

Rueckert D, Sonoda LI, Hayes C, Hill DL, Leach MO, Hawkes DJ. Nonrigid registration using freeform deformations: application to breast MR images. IEEE Trans Med Imaging. 1999; 18:712721. [PubMed: 10534053] 
Rujescu D, Bender A, Keck M, Hartmann AM, Ohl F, Raeder H, Giegling I, Genius J, McCarley RW, Moller HJ, Grunze H. A pharmacological model for psychosis based on N-methyl-D-aspartate receptor hypofunction: molecular, cellular, functional and behavioral abnormalities. Biol Psychiatry. 2006; 59:721-729. [PubMed: 16427029]

Scott-Van Zeeland AA, Abrahams BS, Alvarez-Retuerto AI, Sonnenblick LI, Rudie JD, Ghahremani D, Mumford JA, Poldrack RA, Dapretto M, Geschwind DH, Bookheimer SY. Altered functional connectivity in frontal lobe circuits is associated with variation in the autism risk gene CNTNAP2. Sci Transl Med. 2010; 2:56ra80.

Smith SM. Fast robust automated brain extraction. Hum Brain Mapp. 2002; 17:143-155. [PubMed: 12391568]

Smith SM, Jenkinson M, Johansen-Berg H, Rueckert D, Nichols TE, Mackay CE, Watkins KE, Ciccarelli O, Cader MZ, Matthews PM, Behrens TE. Tract-based spatial statistics: voxelwise analysis of multi-subject diffusion data. Neuroimage. 2006; 31:1487-1505. [PubMed: 16624579]

Song SK, Sun SW, Ju WK, Lin SJ, Cross AH, Neufeld AH. Diffusion tensor imaging detects and differentiates axon and myelin degeneration in mouse optic nerve after retinal ischemia. Neuroimage. 2003; 20:1714-1722. [PubMed: 14642481]

Spoletini I, Cherubini A, Di Paola M, Banfi G, Rusch N, Martinotti G, Bria P, Rubino IA, Siracusano A, Caltagirone C, Spalletta G. Reduced fronto-temporal connectivity is associated with frontal gray matter density reduction and neuropsychological deficit in schizophrenia. Schizophr Res. 2009; 108:57-68. [PubMed: 19097861]

Stein MB, Yang BZ, Chavira DA, Hitchcock CA, Sung SC, Shipon-Blum E, Gelernter J. A common genetic variant in the neurexin superfamily member CNTNAP2 is associated with increased risk for selective mutism and social anxiety-related traits. Biol Psychiatry. 2011; 69:825-831. [PubMed: 21193173]

Stephan KE, Friston KJ, Frith CD. Dysconnection in schizophrenia: from abnormal synaptic plasticity to failures of self-monitoring. Schizophr Bull. 2009; 35:509-527. [PubMed: 19155345]

Stone JL, O'Donovan MC, Gurling H, Kirov GK, Blackwood DH, Corvin A. Rare chromosomal deletions and duplications increase risk of schizophrenia. Nature. 2008; 455:237-241. [PubMed: 18668038]

Strauss KA, Puffenberger EG, Huentelman MJ, Gottlieb S, Dobrin SE, Parod JM, Stephan DA, Morton DH. Recessive symptomatic focal epilepsy and mutant contactin-associated protein-like 2. N Engl J Med. 2006; 354:1370-1377. [PubMed: 16571880]

Tan GC, Doke TF, Ashburner J, Wood NW, Frackowiak RS. Normal variation in fronto-occipital circuitry and cerebellar structure with an autism-associated polymorphism of CNTNAP2. Neuroimage. 2010; 53:1030-1042. [PubMed: 20176116]

Vernes SC, Newbury DF, Abrahams BS, Winchester L, Nicod J, Groszer M, Alarcon M, Oliver PL, Davies KE, Geschwind DH, Monaco AP, Fisher SE. A functional genetic link between distinct developmental language disorders. N Engl J Med. 2008; 359:2337-2345. [PubMed: 18987363]

Wang KS, Liu XF, Aragam N. A genome-wide meta-analysis identifies novel loci associated with schizophrenia and bipolar disorder. Schizophr Res. 2010; 124:192-199. [PubMed: 20889312]

Whalley HC, O'Connell G, Sussmann JE, Peel A, Stanfield AC, Hayiou-Thomas ME, Johnstone EC, Lawrie SM, McIntosh AM, Hall J. Genetic variation in CNTNAP2 alters brain function during linguistic processing in healthy individuals. Am J Med Genet B Neuropsychiatr Genet. 2011; 156B:941-948. [PubMed: 21987501]

Whitehouse AJ, Bishop DV, Ang QW, Pennell CE, Fisher SE. CNTNAP2 variants affect early language development in the general population. Genes Brain Behav. 2011; 10:451-456. [PubMed: 21310003]

Winterer G, Konrad A, Vucurevic G, Musso F, Stoeter P, Dahmen N. Association of 5' end neuregulin-1 (NRG1) gene variation with subcortical medial frontal microstructure in humans. Neuroimage. 2008; 40:712-718. [PubMed: 18255317]

Wittchen, H.; Zaudig, M.; Fydrich, T. Strukturiertes Klinisches Interview für DSM-IV, Achse I und II. Goettingen: Hogrefe; 1997.

Zhang LI, Poo MM. Electrical activity and development of neural circuits. Nat Neurosci. 2001; 4(Suppl):1207-1214. [PubMed: 11687831] 


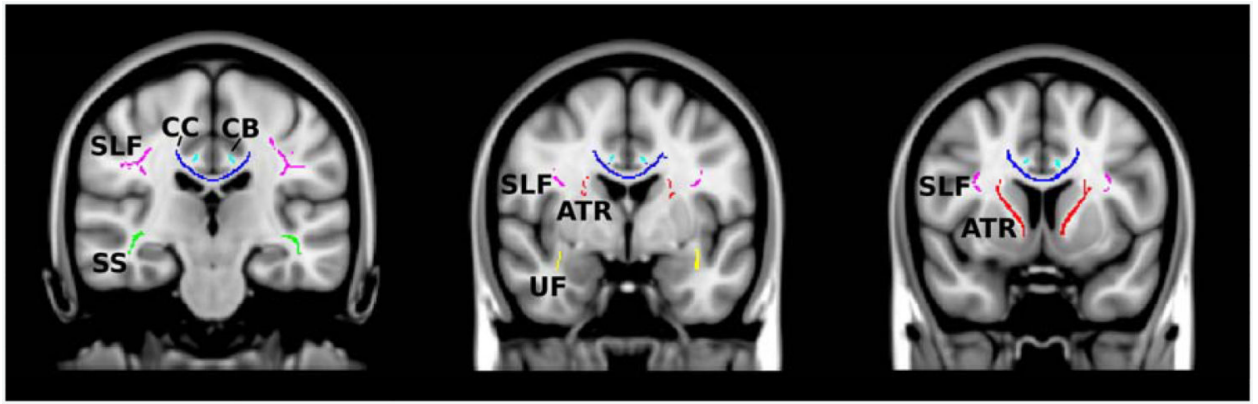

Figure 1.

Regions of interest based on the TBSS white matter skeleton and Johns Hopkins University (JHU) ICBMDTI-81 White-Matter Labels Atlas (Hua et al., 2008; Mori, 2005).

Six major white matter tracts were chosen for analysis: cingulum bundle, cingulate gyrus part (CB, turquoise), corpus callosum (CC, blue), superior longitudinal fasciculus (SLF, pink), anterior thalamic radiation (ATR, red; this comprised the JHU atlas labels "anterior limb of internal capsule" and "anterior corona radiata"), sagittal stratum (SS, green; according to the JHU atlas, this mainly comprises fibers of the inferior fronto-occipital and inferior longitudinal fasciculi), and uncinate fasciculus (UF, yellow). Coronal slices at MNI coordinates $\mathrm{Y}=-23,-2$ and 7 are shown, following the radiological convention (right hemisphere is left on figure). 


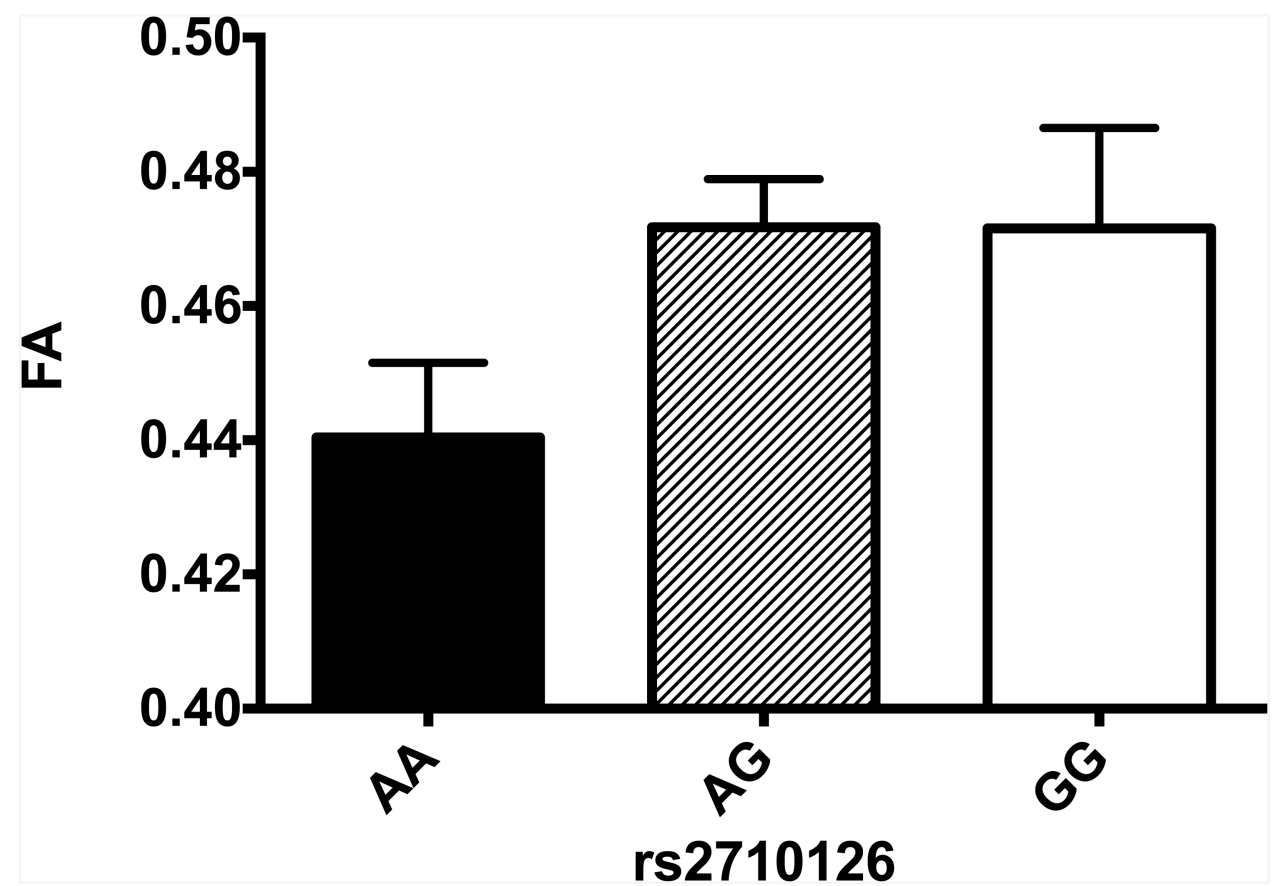

Figure 2.

rs2710126 genotype groups differ in Fractional Anisotropy in the uncinate fasciculus. This genotype effect appears recessive, i.e., only homozygotes of the presumed risk allele (A) have lower Fractional Anisotropy. Error bars indicate 95\% confidence intervals 


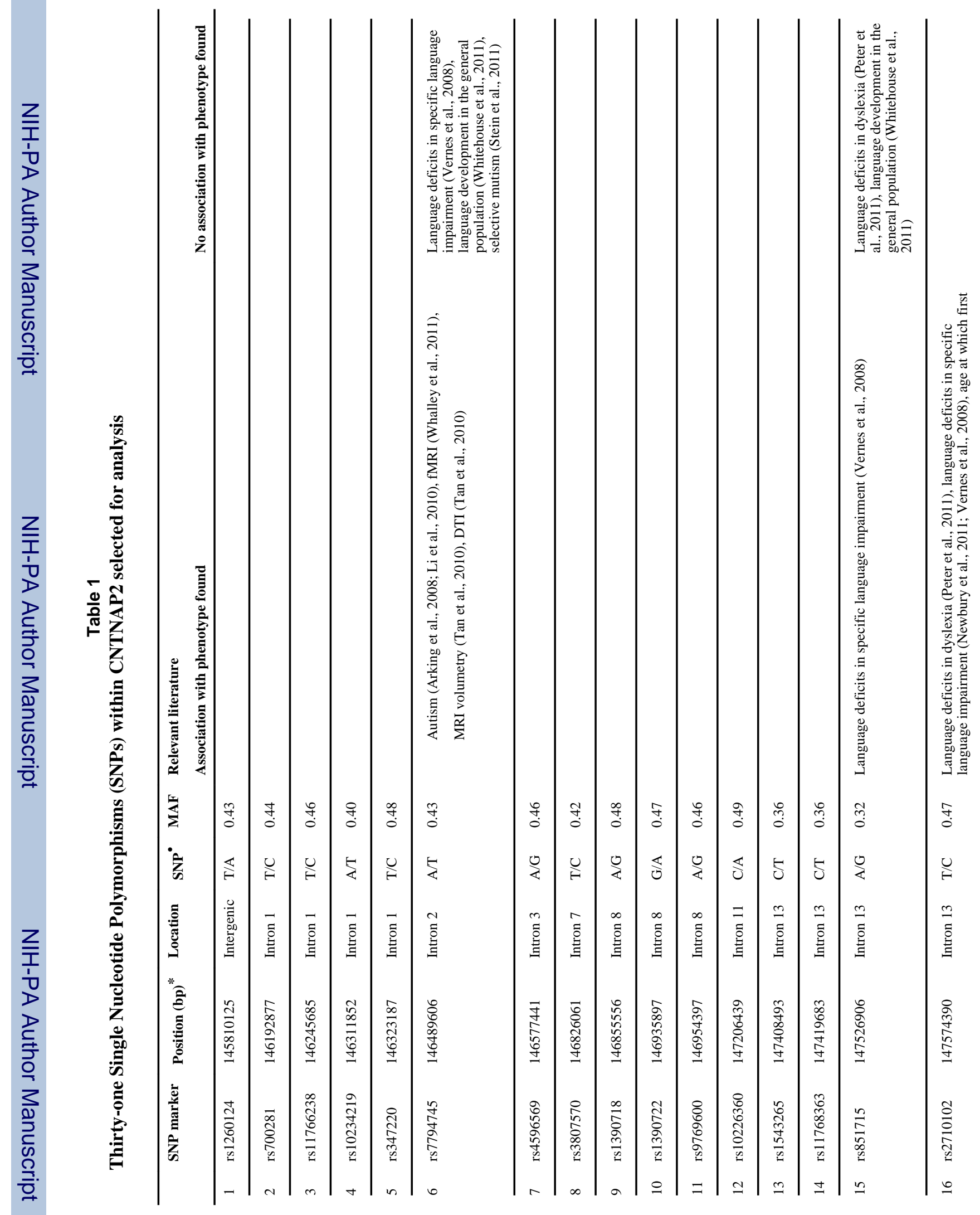




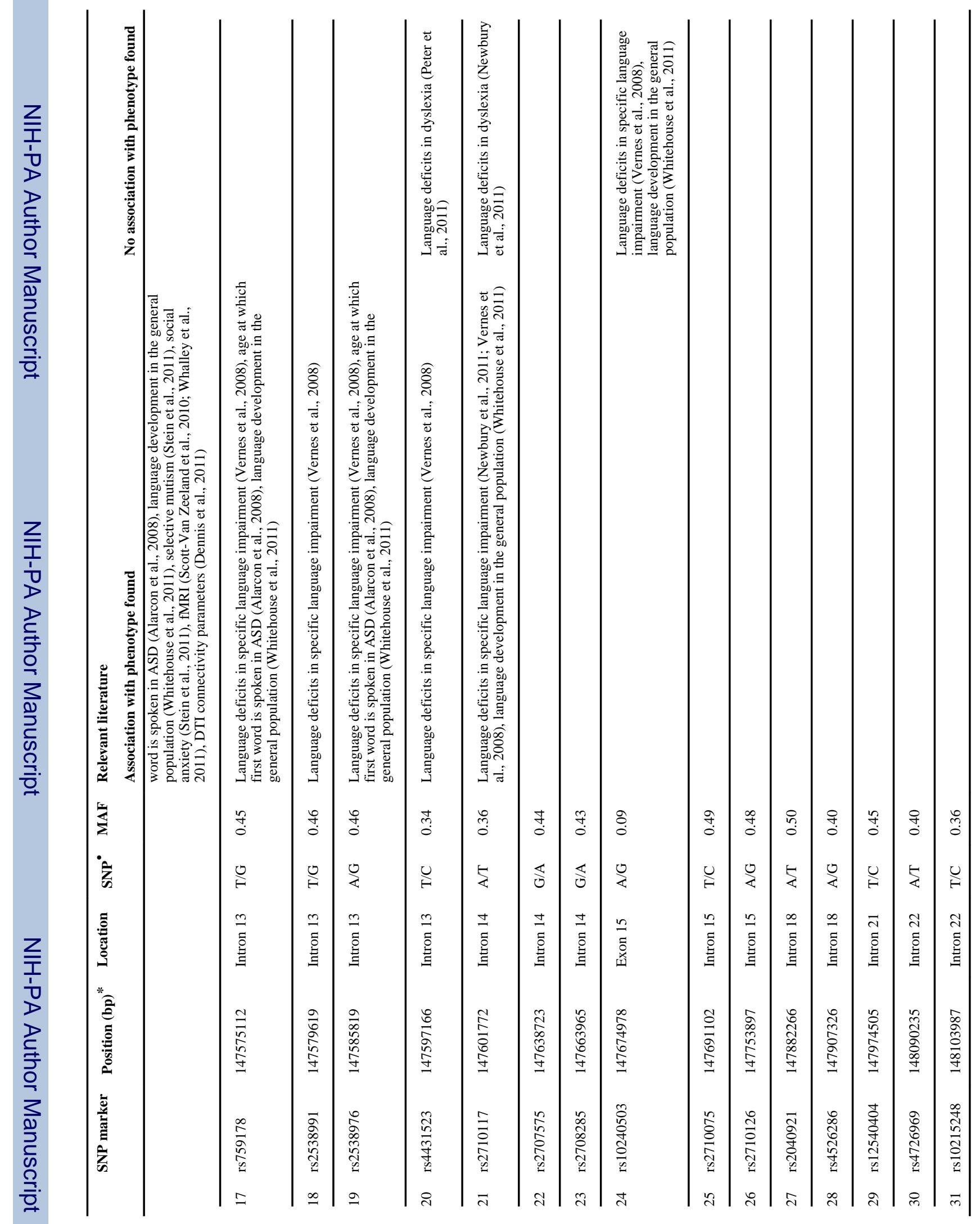




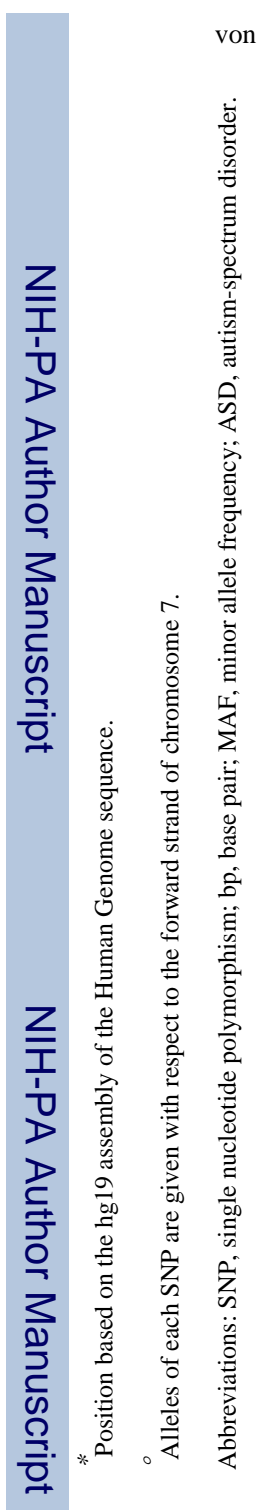

von Hohenberg et al.

Page 17

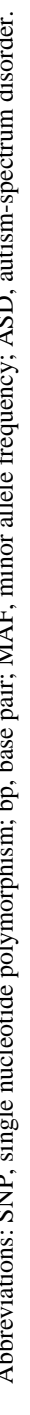




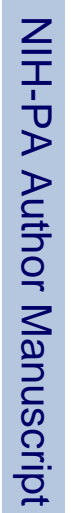

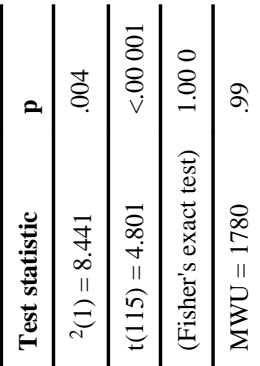
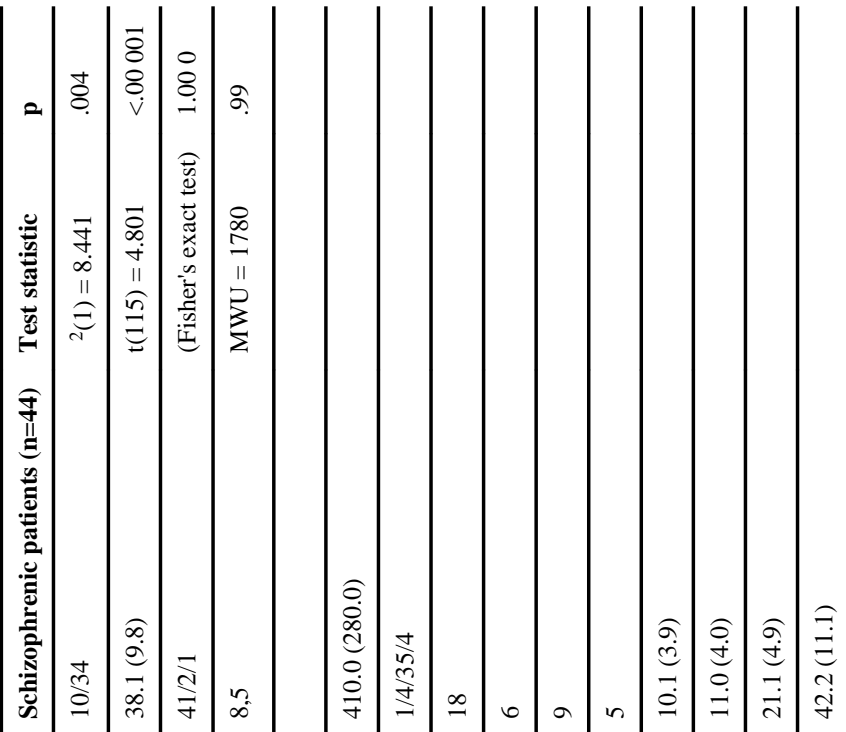

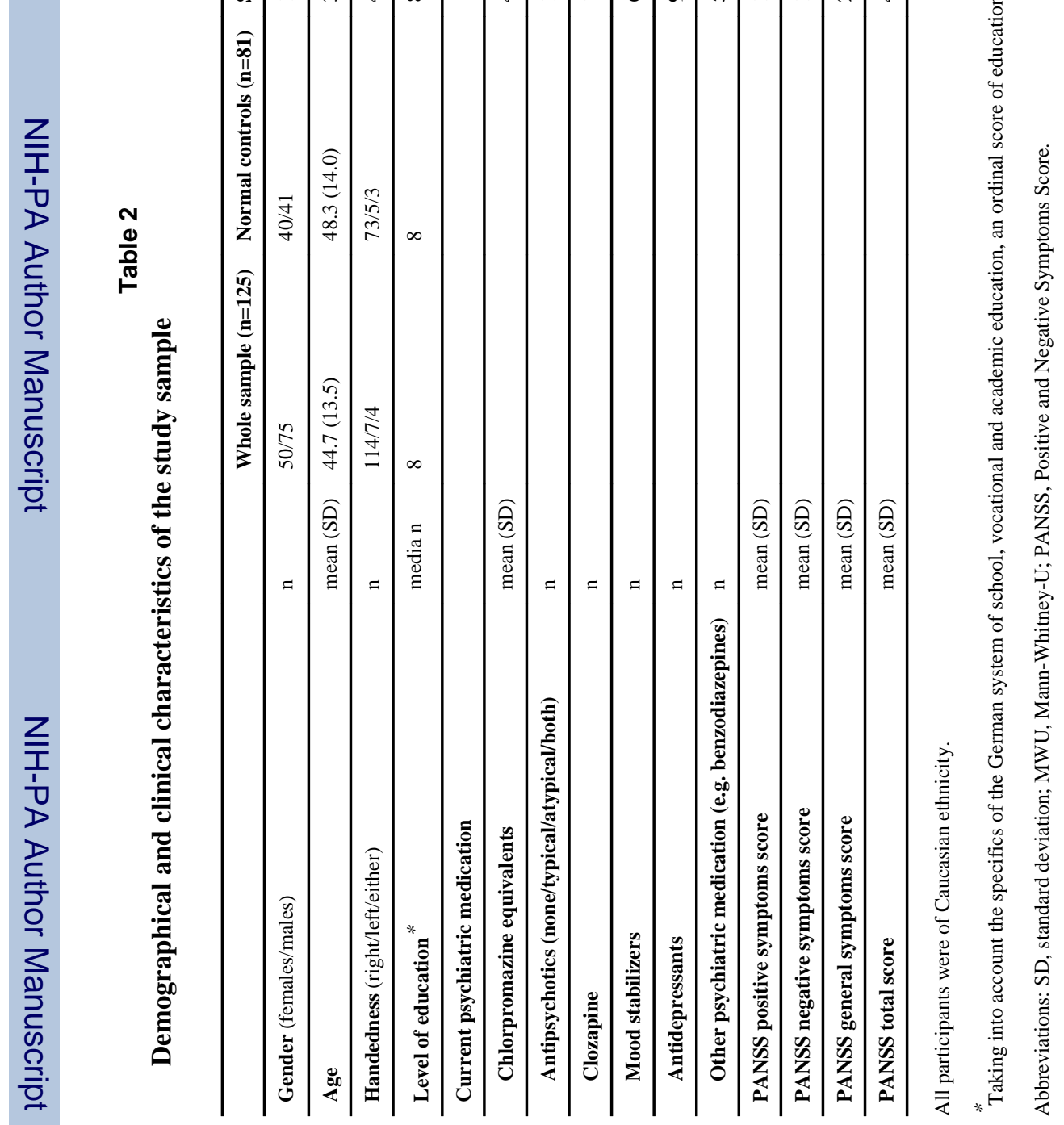




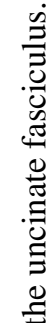

우

齐

ลे

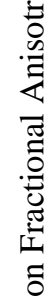

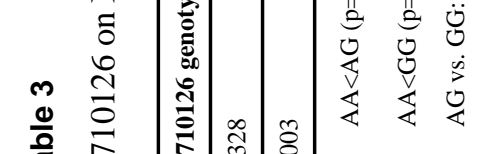

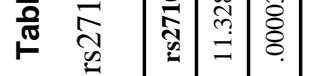

\begin{tabular}{|c|c|c|c|}
\hline 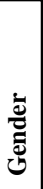 & 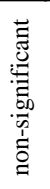 & & \\
\hline$\stackrel{8}{4}$ & $\begin{array}{l}\infty \\
0 \\
\infty \\
\infty \\
\infty\end{array}$ & 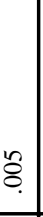 & 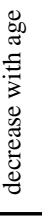 \\
\hline 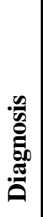 & $\begin{array}{l} \\
\overparen{1} \\
+ \\
+\end{array}$ & 8 & 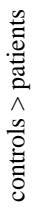 \\
\hline$\frac{\bar{\Xi}}{\bar{g}}$ & 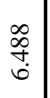 & ఫิ & \\
\hline & \pm & $=$ & 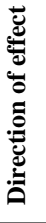 \\
\hline
\end{tabular}

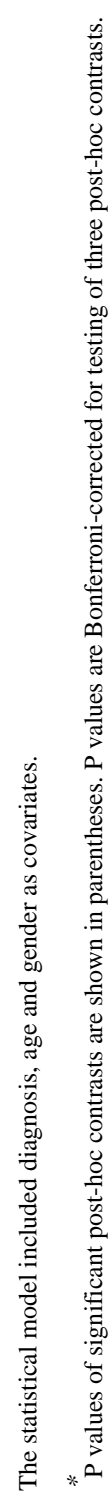

J Psychiatr Res. Author manuscript; available in PMC 2014 October 01. 